\title{
Integrated Rogowski Coil Sensor for Press-Pack Insulated Gate Bipolar Transistor Chips
}

\author{
Chaoqun Jiao ${ }^{1, *}$, Zuoming Zhang ${ }^{2}$, Zhibin Zhao ${ }^{3}$ and Xiumin Zhang ${ }^{1}$ \\ 1 School of Electrical Engineering, Beijing Jiaotong University, No.3 ShangYuanCun, Haidian District, \\ Beijing 100044, China; xmzhang@bjtu.edu.cn \\ 2 Rizhao Power Supply Company of State Grid Shandong Electric Power Company, Yantai Road 68, \\ Donggang District, Rizhao, Shandong 276800, China; 18126182@bjtu.edu.cn \\ 3 State Key Laboratory of Alternate Electrical Power System with Renewable Energy Sources, North China \\ Electric Power University, No.2, Beinong Road, Changping District, Beijing 102206, China; \\ zhibinzhao@ncepu.edu.cn \\ * Correspondence: chqjiao@bjtu.edu.cn; Tel.: +86-158-1046-1086
}

Received: 29 June 2020; Accepted: 20 July 2020; Published: 22 July 2020

check for updates

\begin{abstract}
Recently, the press-pack insulated gate bipolar transistor (IGBT) has usually been used in direct current (DC) transmission. The press-pack IGBT (PPI) adopts a parallel layout of boss chips, and the currents of each chip will be uneven in the process of turning on and off, which will affect the reliability of the device. To measure the currents of each chip, based on the analysis of the principle and equivalent model of the Rogowski coil, this paper puts forward the design scheme and design index of multi-layer printed circuit board (PCB) Rogowski coil with good high-frequency performance, strong anti-interference ability and sufficient sensitivity. With the simulation analysis of Altium Designer and ANSYS softwares, a $1 \mathrm{~mm}$ thick, 76-turn integrated four-layer PCB Rogowski coil is designed. Then, adding a composite integrator, an integrated Rogowski coil sensor for measurement of PPI chips currents is designed. The Pspice simulation and the experiment results show that the sensor is fully satisfied with the chip current measurement.
\end{abstract}

Keywords: Press-Pack IGBT (PPI); Chip reliability; PCB Rogowski Coil; Current measurement

\section{Introduction}

Flexible direct current (DC) transmission has been widely developed with its more flexible and reliable transmission mode. In order to maintain the safe operation of the system, more reliable requirements are put forward for the controllable rectifiers, usually an insulated gate bipolar transistor (IGBT), which constitute the flexible converter. Compared with welded IGBT, the press-pack IGBT (PPI) has a longer service life, a unique short-circuit failure mode, and high current-carrying capacity. Generally, multiple chips of PPI are connected in parallel to increase the PPI current level. However, due to the layout of the boss chips, it will inevitably make the current of each chip unequal and the internal chip current overshoot during the turn-on and turn-off, This will affect the reliability of the device. For reliability of the PPI, it needs to measure the currents of each chips in the PPI [1-10].

A Rogowski coil current sensor is widely used to monitor the transient current in power electronic applications without external magnetic field interference. The Rogowski coil can be divided into a hard Rogowski coil, flexible Rogowski coil and PCB Rogowski coil. The hard Rogowski coil adopts a rigid framework, which is not easy to deform, with dense winding, high accuracy and poor adaptability. The flexible Rogowski coil adopts a flexible framework, which can be deformed, is easy to measure, and has sparse winding, but the winding accuracy is not as good as that of the hard coil. A PCB Rogowski coil printed on a PCB is not easy to deform, and its winding accuracy is greatly improved, 
but the space is limited, the cross-sectional area is small, and the number of turns is small, resulting in a small mutual inductance. Because they are hollow coils, they can be directly nested on the conductor under test, and the alternating current (AC) can be measured without contact.

As early as 1989 and 1991, Li Haiyan designed a Rogowski coil for measuring steep pulses. The coil adopts self integration and the sensitivity is $1 \mathrm{mV} / \mathrm{A}[11,12]$. In 2008, Wei Bing et al. undertook a detailed analysis of the frequency response of the passive integrator, and proposed the design of the coaxial integrator with through-hole ceramic chip capacitor and multiple resistors in series to reduce the stray parameters, achieving a good effect, with a frequency band of 0.18-17.3 MHz [13]. In 2011 and 2013, D. Gerber, T. Guillod designed a PCB Rogowski coil with a coil bandwidth of more than 28 $\mathrm{MHz}$ and a time delay of $11 \mathrm{~ns}$ for over-current detection of a $4.5 \mathrm{kV}$ PPI gate drive circuit. In this paper, the equivalent model of Rogowski coil and the prediction of parameters are established, and the accuracy of prediction is verified by measurement [14,15]. In 2013, Dr. Xiang Minjiang designed a passive and active composite integrated circuit with a bandwidth of $10 \mathrm{~Hz} \sim 1 \mathrm{MHz}$ for the acquisition of traveling wave signals in intelligent substations [16]. In 2016, Yadong Liu designed a PCB Rogowski coil for overhead transmission [17]. In 2016, Tao Tao designed a PCB Rogowski coil for the analysis of the anti-interference property [18]. In 2016, M. Tsukuda designed a micro PCB Rogowski coil for current monitoring and protection of a high-voltage power module. In 2017, they proposed a new idea for the clamp type PCB sensor, which is used for the current measurement of the intelligent power module and power electronic converter [19-21]. In 2016, Yang Jun et al. designed an active and flexible Rogowski coil, which is used for the measurement and collection of lightning current. The bandwidth is from hundreds $\mathrm{Hz}$ to tens of $\mathrm{MHz}$, solving the problem of low sensitivity of passive RC integration [22]. From 2018 to the present, many researcher studied the multilayer PCB Rogowski coil for the measurement of precise impulse current and lightning current [23-27]. However, these coils are circular and can only measure precise impulse current and lightning current. The mutual inductance values of a square coil are larger than a circular coil with the same number of turns and cross-section area, which shows that square mutual inductance has more advantages. Moreover, to measure the multi-chip currents in the IGBT, a 4-coil integrated PCB Rogowski coil sensor is designed in this paper, but the coils in [23-27] are a single coil.

Due to the characteristics of large voltage and high current, the PPI is suitable for the converter of power systems. The reliability of the PPI is of great significance for the safe operation of the system. In this paper, an integrated Rogowski coil current transformer based on PCB is designed to monitor the breaking current of PPI in real time. Because the sensor is embedded, it can not only detect the current without changing the structure of the tested system, but also ensure the safe and reliable operation of the power system. As a kind of current sensor, it can also provide reference for the analysis of PPI characteristics, such as the current-sharing characteristics of PPI.

\section{Design and Simulation of PCB Rogowski Coil Sensor}

The working principle of the Rogowski coil and establishment of Rogowski coil equivalent model has been developed in [28-31]. According the characters of the currents in the IGBT, the design index of the sensor is the sensitivity (above $40 \mathrm{mV} / \mathrm{A}$ ), bandwidth (not below $2 \mathrm{MHz}$ ) and measurement capability $(0-100 \mathrm{~A})$.

\subsection{The Design of the Single PCB Rogowski Coil}

Figure 1 shows the $4.5 \mathrm{kV} / 1.2 \mathrm{kA}$ crimped IGBT structure of westcode, UK. It is composed of 11 IGBT chips and 5 anti parallel diodes with gaps. Each chip is $9.4 \mathrm{~mm} \times 9.4 \mathrm{~mm} \times 9.4 \mathrm{~mm}$.

According to the structure of a PPI boss, two kinds of coils of circular and square structure are designed as shown in Figure 2. Under certain space conditions, the circle is more in line with the trend of the magnetic field, while the square is more in line with the IGBT boss structure, and the space utilization rate is large. The square and circular coils with the same number of turns and cross-sectional area are simulated in ANSYS. The measured mutual inductance values are 2.7112 and 
2.1634, respectively. The square mutual inductance has more advantages. Therefore, this paper finally adopts a 4-layer square plate structure with keel and return line, which can remove the unnecessary magnetic flux path of the wire turn and return line, reduce the influence of external current, effectively reduce the external signal interference, and make PCB technology reach the maximum limit. The structure of each layer of the Rogowski coil with square PCB is shown in Figure 3.

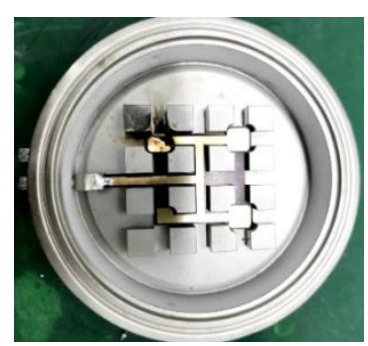

Figure 1. Outline structure of press-pack insulated gate bipolar transistor (PPI).
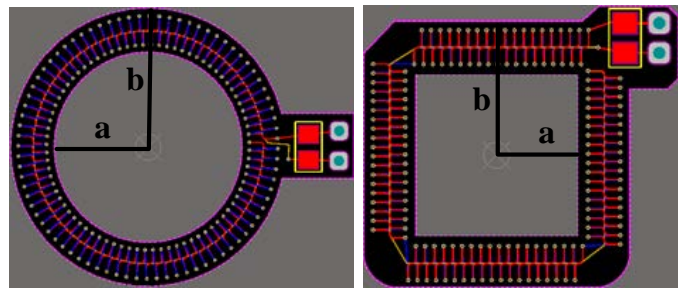

(a) $a=6.7 \mathrm{~mm} b=9.8 \mathrm{~mm}$ (b) $a=4.8 \mathrm{~mm} b=7.9 \mathrm{~mm}$

Figure 2. Dimensional drawings of Rogowski coils with different structures.

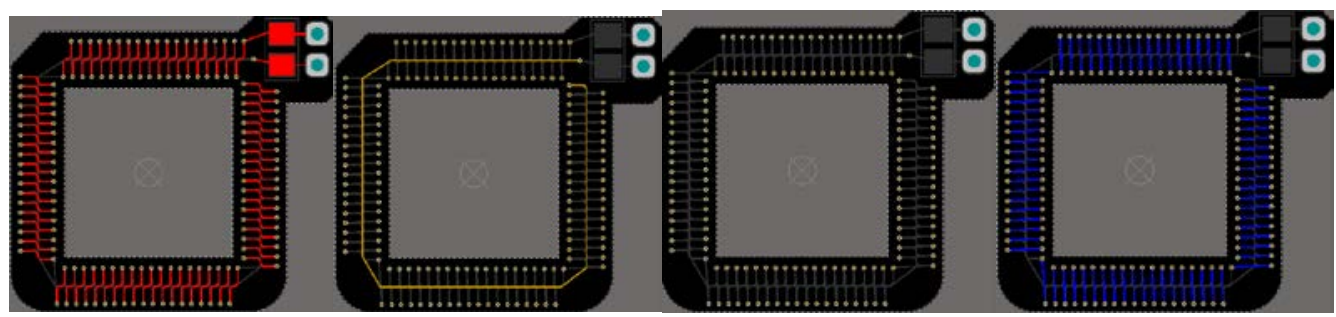
(a) First layer
(b) Second layer
(c) Third layer
(d) Fourth layer

Figure 3. Fishbone-type four-layer board design pattern with return line.

The PCB Rogowski coil is processed by the PCB manufacturer, and the finished product is shown in Figure 4. The pad part is used for welding terminal resistance, and the through hole is used for connecting the external circuit.

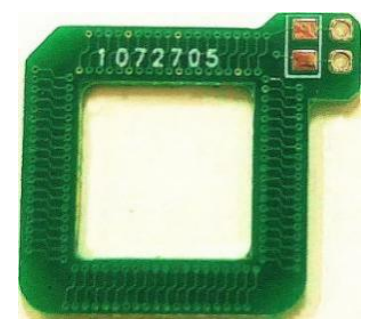

Figure 4. PCB Rogowski Coil physical map. 


\subsection{Design of the Integrated PCB Rogowski Coil}

Multiple single coils can be used to measure the multi chip current, but the operation is tedious and the error is easily increased due to improper human placement and other factors. In order to solve the above problems, this paper integrates multiple coils into a PCB, which not only can realize the measurement of a multi-chip current, but also has the advantages of simple operation, high integration and small error. As shown in Figure 5, according to the size of the PPI module, a three-dimensional structure diagram of the PPI is established. Two excitation sources, source and sink, are set at the top and bottom of the notch boss (single IGBT chip). Four special bosses are selected for joint simulation to calculate the mutual inductance between the coil and 11 bosses. The arrangement is shown in Table 1 .

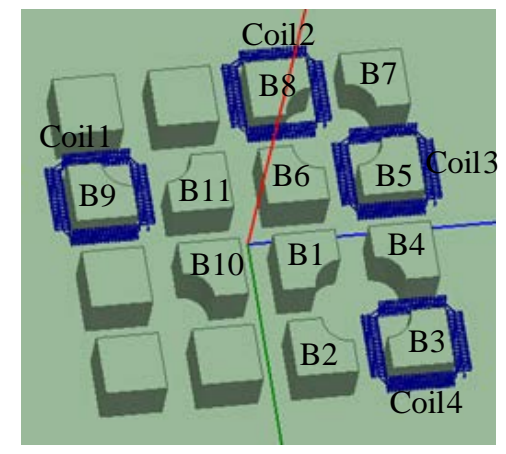

Figure 5. Joint simulation model.

Table 1. Simulation results of the mutual inductance $(\mathrm{nH})$ between the 4 coils and 11 bosses.

\begin{tabular}{ccccc}
\hline Name & Coil1 & Coil2 & Coil3 & Coil4 \\
\hline B1 & 0.0444 & 0.0287 & 0.0198 & 0.0347 \\
B2 & 0.0383 & 0.0205 & 0.0013 & 0.0342 \\
B3 & 0.0292 & 0.0191 & 0.0160 & 2.7923 \\
B4 & 0.0337 & 0.0261 & 0.0349 & 0.0055 \\
B5 & 0.0322 & 0.0258 & 2.8324 & 0.0159 \\
B6 & 0.0466 & 0.0536 & 0.0220 & 0.0195 \\
B7 & 0.0203 & 0.0689 & 0.0072 & 0.0111 \\
B8 & 0.0161 & 2.7808 & 0.0450 & 0.0134 \\
B9 & 2.7385 & 0.0046 & 0.0031 & 0.0104 \\
B10 & 0.0428 & 0.0124 & 0.0050 & 0.0145 \\
B11 & 0.0835 & 0.0076 & 0.0035 & 0.0145 \\
\hline
\end{tabular}

It can be seen from the table that there is mutual inductance between the coil and the surrounding boss, and the closer the distance is, the greater the mutual inductance value is, but it is far less than the mutual inductance between the measured conductor and the coil, and the error is very small, which also shows that the PCB coil designed in this paper has certain anti-interference ability. The PCB board designed by Altium Designer(AD) and the actual processing drawing are shown in Figure 6.

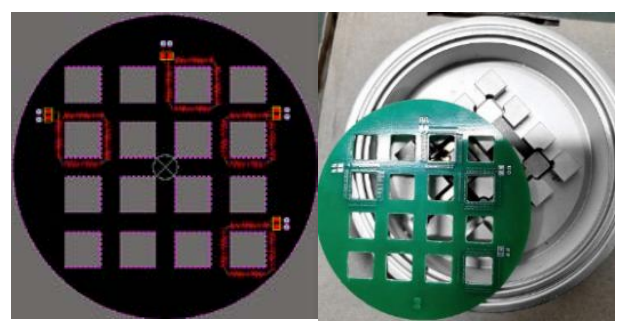

Figure 6. Integrated PCB design and physical drawing. 


\subsection{Impedance Analysis of Rogowski Coil}

The impedance analysis of PCB Rogowski coil can extract the corresponding electromagnetic parameters and analyze the amplitude frequency phase frequency characteristics of a PCB Rogowski coil. Two impedance analysis methods, the simulation method and the experimental method, are used to analyze and compare the coil, as shown in Figure 7.
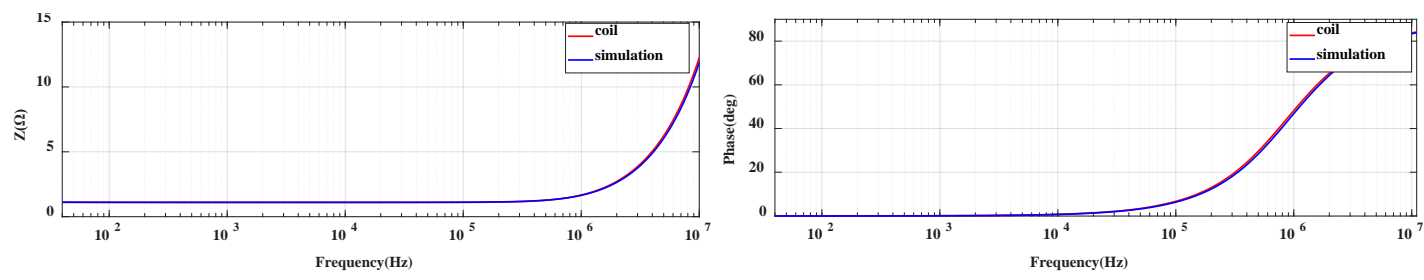

Figure 7. Comparison of simulation and experimental impedance analysis of coil head.

After verifying the impedance of a single coil, the scanning analysis of four coils in the frequency band of $40 \mathrm{~Hz}-100 \mathrm{MHz}$ is carried out in this paper. The frequency characteristic curve of the coil impedance is shown in Figure 8.
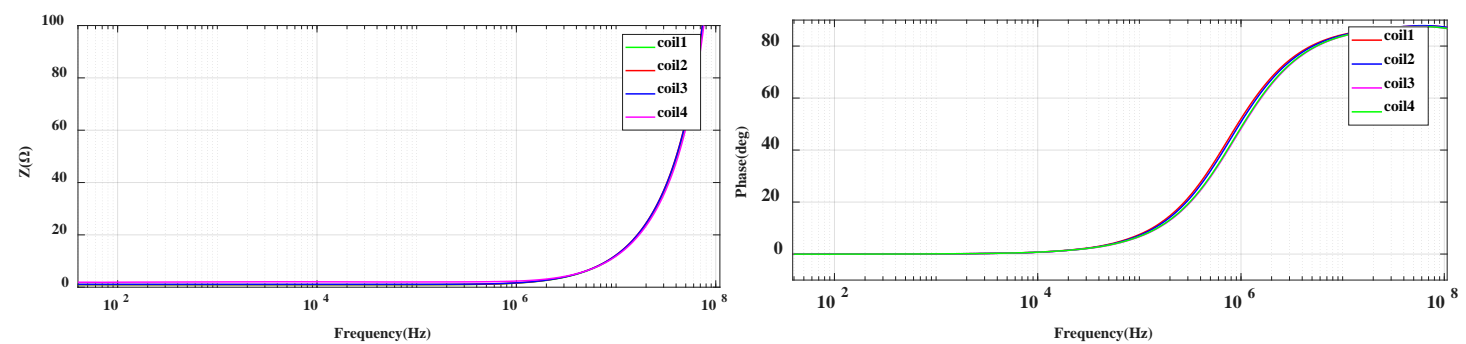

Figure 8. Impedance analysis of integrated PCB coils.

It can be seen from the frequency curve that the impedance and phase frequency of the four coils of the PCB integrated board designed in this paper are basically the same in the frequency band of $40 \mathrm{~Hz}-100 \mathrm{MHz}$, and there is no resonance point. To some extent, it avoids the parameter difference caused by the uneven number of hand winding turns, and proves the consistency of the parameters of the integrated coil. Combined with the experiment and simulation analysis, the final PCB coil parameters are shown in Table 2.

Table 2. Parameter table of PCB Rogowski coil.

\begin{tabular}{ccccccccc}
\hline Turns & $\begin{array}{c}\text { Inner } \\
\text { Edge }\end{array}$ & $\begin{array}{c}\text { Outer } \\
\text { Edge }\end{array}$ & Thickness & $\begin{array}{c}\text { Line } \\
\text { Width }\end{array}$ & $\begin{array}{c}\text { Internal } \\
\text { Resistance }\end{array}$ & Capacitance & $\begin{array}{c}\text { Self } \\
\text { Inductance }\end{array}$ & $\begin{array}{c}\text { Mutual } \\
\text { Inductance }\end{array}$ \\
\hline 76 & $9.6 \mathrm{~mm}$ & $15.8 \mathrm{~mm}$ & $1 \mathrm{~mm}$ & $3.5 \mathrm{mil}$ & $1.401 \Omega$ & $0.9 \mathrm{pF}$ & $411 \mathrm{nH}$ & $5.41 \mathrm{nH}$ \\
\hline
\end{tabular}

\section{Overall Circuit Design and Simulation Based on Compound Integrator}

Passive integration is suitable for measuring high-frequency current, and its working characteristics are relatively poor at low-frequency. Active integration is just the opposite, which is suitable for measuring low-frequency current, and its high-frequency characteristics are relatively poor. In order to realize the accurate measurement of the chip current of the PPI module, the integrator should be designed to realize the reduction of PCB Rogowski coil differential signal in a wide frequency band. Based on the above analysis, this paper selects a scheme of composite integrator, which combines active integration and passive integration as shown in Figure 9. In the low-frequency segment, active integration is responsible for integration, while in the high-frequency segment, unit gain has no effect 
on the signal; in the high-frequency segment, passive integration is responsible for integration, while in the low-frequency segment, unit gain has no effect on the signal.

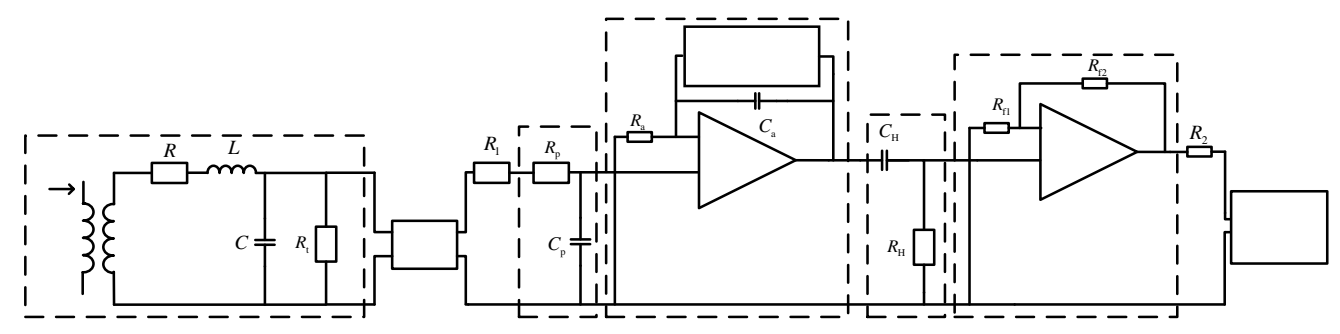

Figure 9. PCB Rogowski coil sensor overall design circuit diagram.

When the measured current $i$ is induced to the Rogowski coil, the Rogowski coil outputs a current differential signal, which is transmitted to the passive integrator through the coaxial cable, integrating the high-frequency part of the signal, integrating the low-frequency part of the signal through the in-phase active integrator, and filtering the low-frequency noise and DC drift generated by the operational amplifier through the high-pass filter The filter further filters the low-frequency noise of the signal, amplifies the signal through the buffer amplifier, and finally outputs the signal to the oscilloscope for display.

\subsection{Simulation Analysis of Alternating Current (AC) Scanning of PCB Rogowski Coil Sensor}

The overall circuit diagram of PCB Rogowski coil sensor is established in Pspice, and the amplitude frequency phase frequency characteristic diagram is obtained through AC frequency scanning analysis (see Figure 10 below). It can be seen from the phase frequency characteristic diagram of the sensor that the gain of the integrator is kept at about $-28 \mathrm{~dB}$ in the frequency band of $100 \mathrm{~Hz}-5 \mathrm{MHz}$ and the sensitivity is about $40 \mathrm{mV} / \mathrm{A}$. From the phase frequency characteristic diagram, it can be seen that there is a constant $0^{\circ}$ phase in the frequency band of $200 \mathrm{hz}-3 \mathrm{mhz}$. It is worth noting that the blue curve data1 in the figure has high-frequency reflection in the high-frequency section. By adjusting the position of the passive integral resistance, the resistance $R_{\mathrm{P}}$ is moved to the coaxial cable end to solve this problem. After improvement, the data2 curve is obtained.
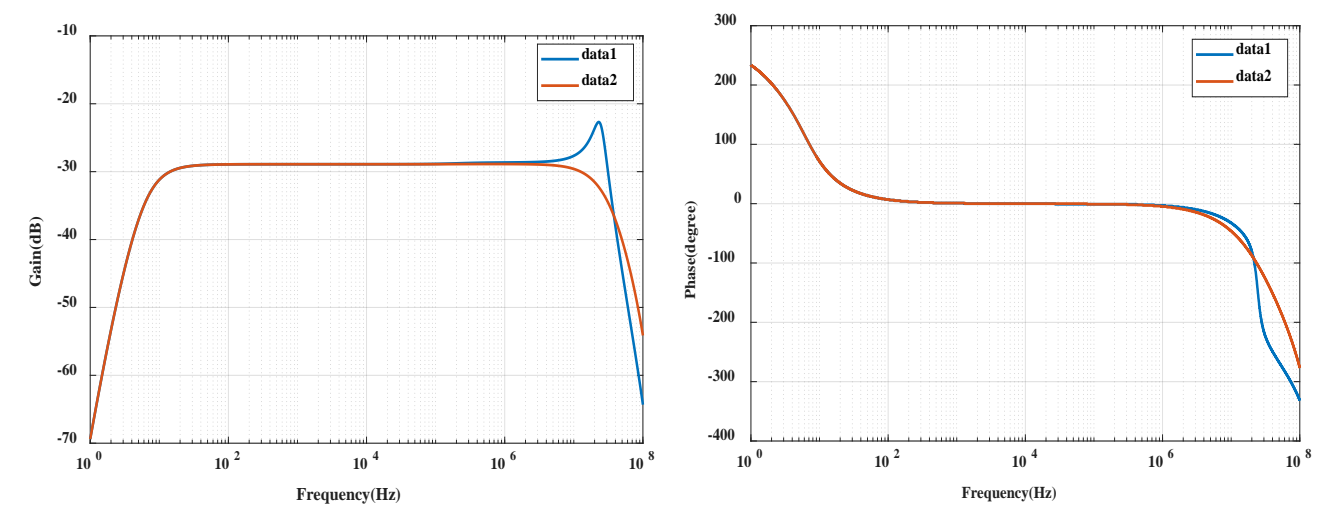

Figure 10. Coil sensor overall amplitude frequency phase frequency characteristic diagram.

\subsection{Transient Simulation Analysis of PCB Rogowski Coil Sensor}

After analyzing the frequency domain of the coil sensor, the sensor is simulated in the time domain to verify the feasibility of the integrator circuit design. The current source in Pspice is changed into different signal sources, such as sine current source (Isin) and pulse signal current source (Pulse). Different frequency and amplitude waveforms can be obtained by setting different parameters. 
(1) Simulation of sinusoidal current

The sinusoidal signal current source has three parameters: bias value (IOFF), peak amplitude (IAMPL) and frequency (FREQ). By setting the above three parameters, four special frequencies (100 $\mathrm{Hz}, 500 \mathrm{~Hz}, 5 \mathrm{MHz}$ and $20 \mathrm{MHz}$ ) are selected, and the current amplitude is $1 \mathrm{~A}$. Select the general settings under time domain (transient), set the running time and step size according to 1000 interval points of 6 cycles, and select 2 cycle waveforms to obtain the following waveforms, as shown in Figure 11.

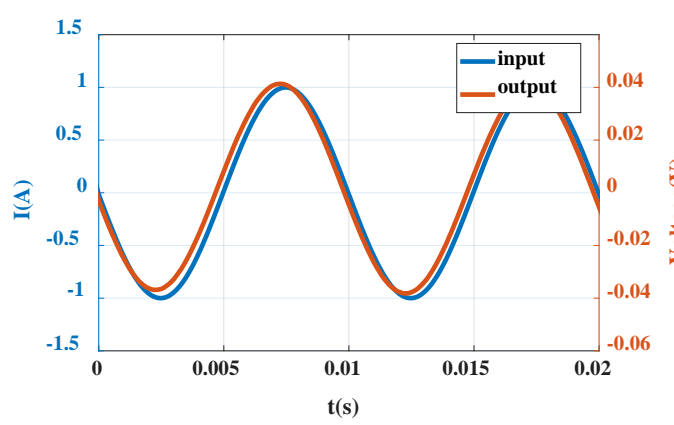

(a) Simulation of $100 \mathrm{~Hz}$

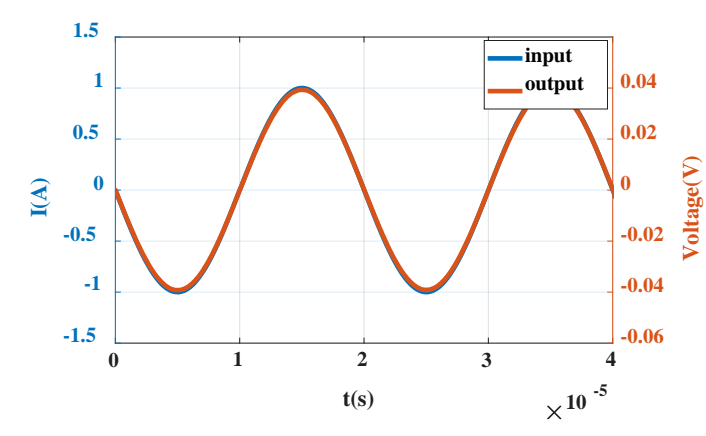

(c) simulation of $5 \mathrm{MHz}$

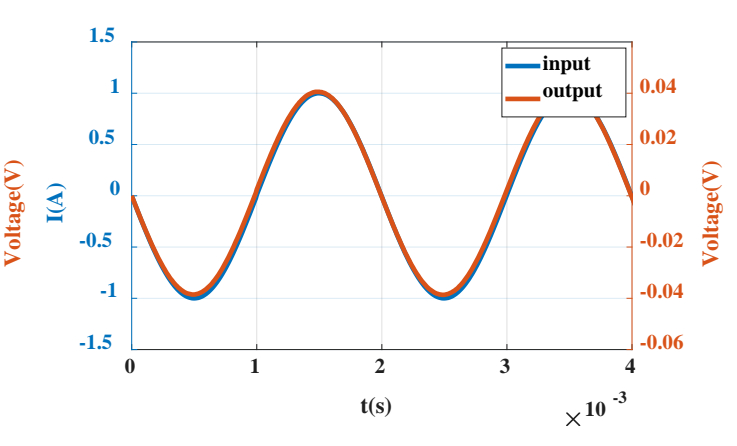

(b) simulation of $500 \mathrm{~Hz}$

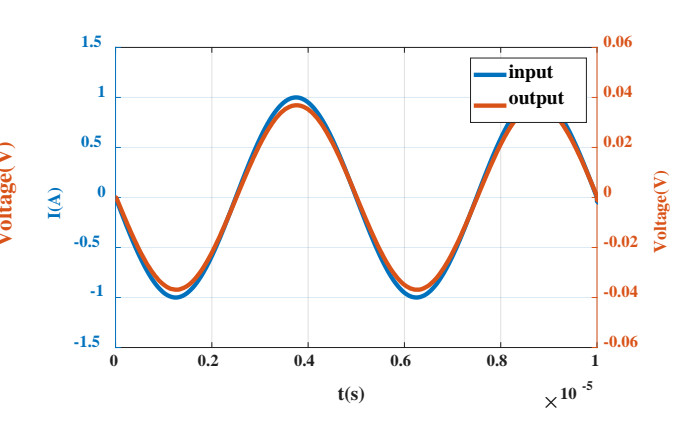

(d) simulation of $20 \mathrm{MHz}$

Figure 11. Sine wave simulation diagrams at different frequencies.

It can be seen from the sine wave in Figure 11 that when the frequency is $100 \mathrm{~Hz}$ and the current input $1 \mathrm{~A}$, the output is $0.04 \mathrm{~V}$ in amplitude, and the phase ratio is slightly ahead; when the frequency range is $500 \mathrm{~Hz}-5 \mathrm{MHz}$, the input and output are consistent, and the sensitivity is kept at $40 \mathrm{mV} / \mathrm{A}$; when the frequency is $20 \mathrm{MHz}$, the output voltage is small, and the phase is shifted backward, the overall output is shifted, and the sensitivity is reduced.

(2) Simulation of square wave current

By setting different parameters of pulse signal current source (Pulse), the square wave current signal with the same amplitude (1A) and different frequency is obtained as the measured current of the sensor, and the waveform is shown in Figure 12. 


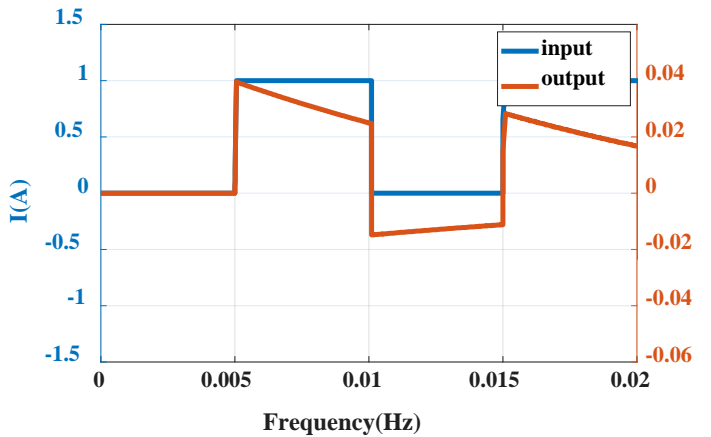

(a) Simulation of $100 \mathrm{~Hz}$

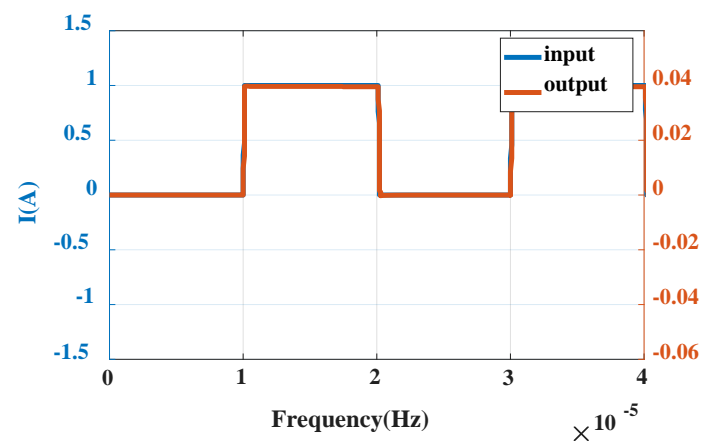

(c) simulation of $5 \mathrm{MHz}$

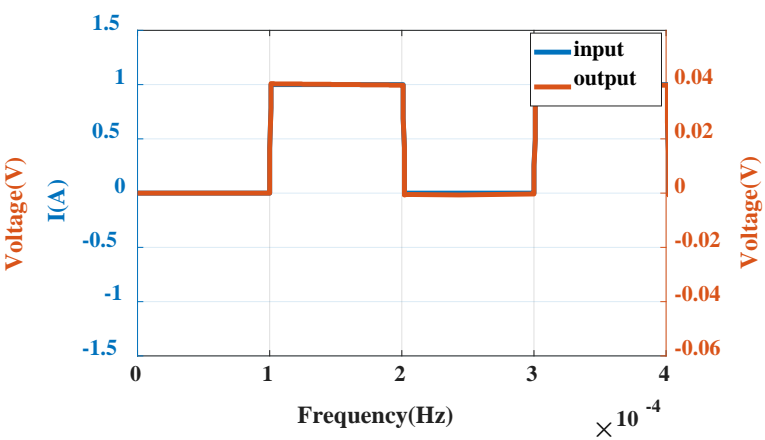

(b) simulation of $5 \mathrm{kHz}$

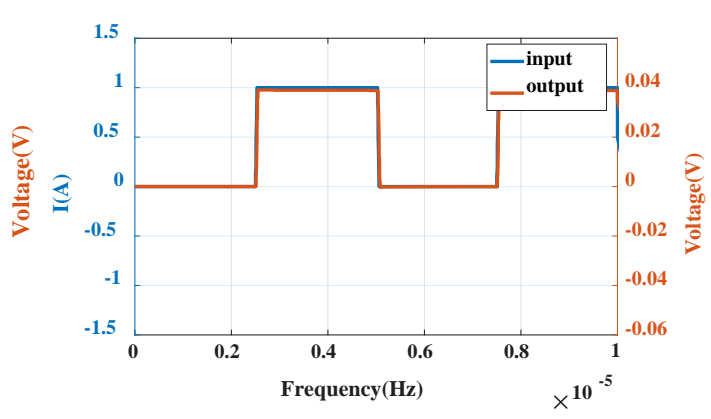

(d) simulation of $20 \mathrm{MHz}$

Figure 12. Simulation of square wave at different frequencies

It can be seen from the square wave signal that the output has a large distortion at $100 \mathrm{~Hz}$, the phase is slightly ahead of the input value, and the output phase is slightly behind the input value at $20 \mathrm{MHz}$. In the simulation of $5 \mathrm{kHz}-5 \mathrm{MHz}$ frequency, the input and output are close to coincidence. When the input peak value is $1 \mathrm{~A}$, the output is $0.04 \mathrm{~V}$ and the sensitivity is kept at $40 \mathrm{mV} / \mathrm{A}$, which can reflect the input current well.

(3) Simulation of triangle wave current

In addition to square wave signal, triangle wave current signal with the same amplitude (1 A) and different frequency can be generated as the measured current of the sensor by setting the parameters of pulse signal current source (Pulse). The waveform is shown in Figure 13.

It can be seen from the triangle wave signal that the phase is slightly ahead at $100 \mathrm{~Hz}$, the output amplitude is distorted, $0.005 \mathrm{~V}$ lower than the ideal value, and the error is $12.5 \%$; at $10 \mathrm{MHz}$, the output phase is slightly behind, $0.003 \mathrm{~V}$ lower than the ideal value, and the error is $7.5 \%$. In the simulation of $5000 \mathrm{~Hz}-5 \mathrm{MHz}$ frequency, the input and output are close to coincidence, which can reflect the input current very well and keep the sensitivity at $40 \mathrm{mV} / \mathrm{A}$.

According to the simulation analysis of the three waveforms, in the low frequency $(100 \mathrm{~Hz})$, the square wave signal distortion is the most serious, and in the high frequency (10 MHz-20 MHz), the performance of the three waveforms is similar. In accordance with the simulation analysis of the amplitude frequency phase frequency of the coil, the sensor has a good measurement ability in the wide frequency of $500 \mathrm{~Hz}-5 \mathrm{MHz}$, and can reflect the measured current well. The results show that the designed PCB Rogowski coil sensor meets the requirements of the switching current frequency of the PPI chip. 


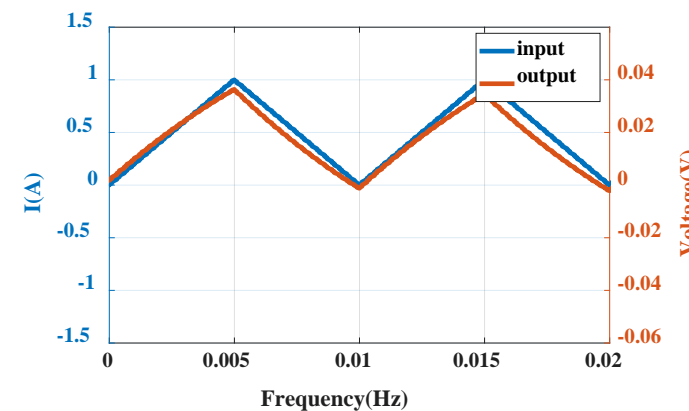

(a) Simulatio $\mathrm{n}$ of $100 \mathrm{~Hz}$

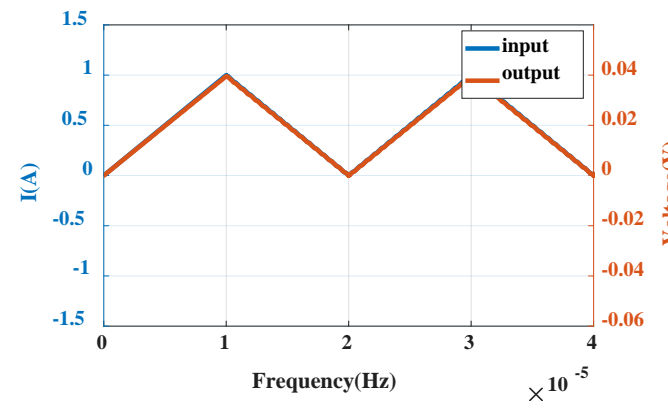

(c) simulation of $5 \mathrm{MHz}$

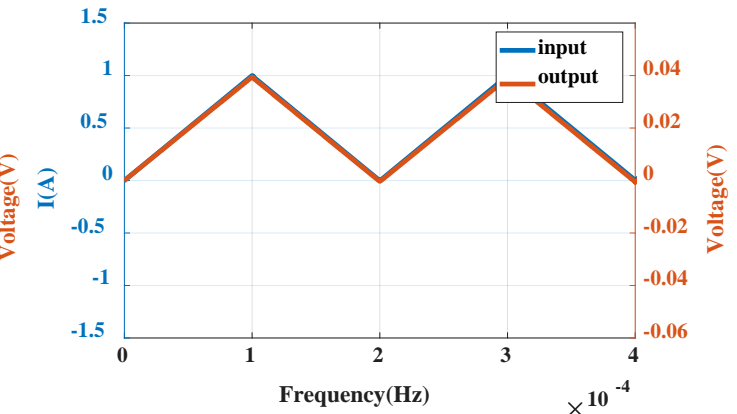

(b) simulation of $5 \mathrm{kHz}$

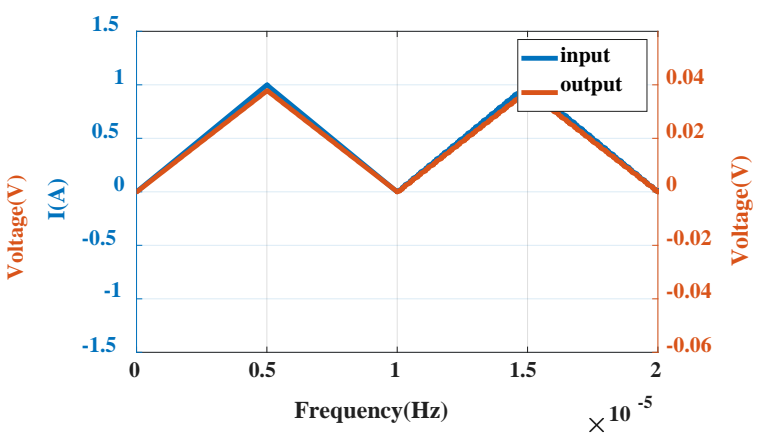

(d) simulation of $10 \mathrm{MHz}$

Figure 13. Triangular wave simulation diagrams at different frequencies

In order to further verify the measurement ability of the Rogowski coil sensor for large current, two current levels of $300 \mathrm{~A}$ and $400 \mathrm{~A}$ are simulated by Pspice with the frequency of $1 \mathrm{MHz}$. The waveform is shown in Figure 14 below.

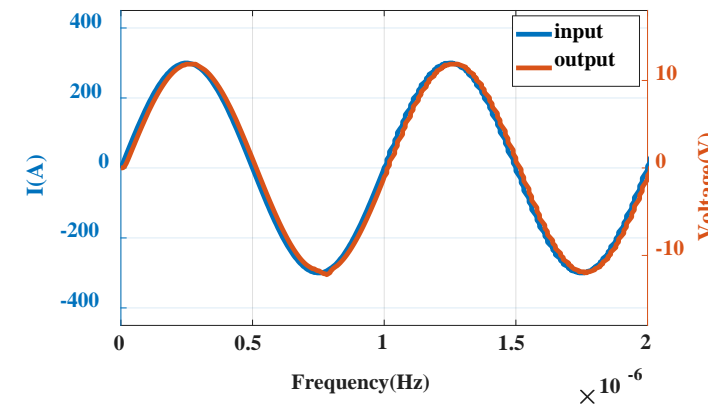

(a) $300 \mathrm{~A}, 1 \mathrm{MHz}$

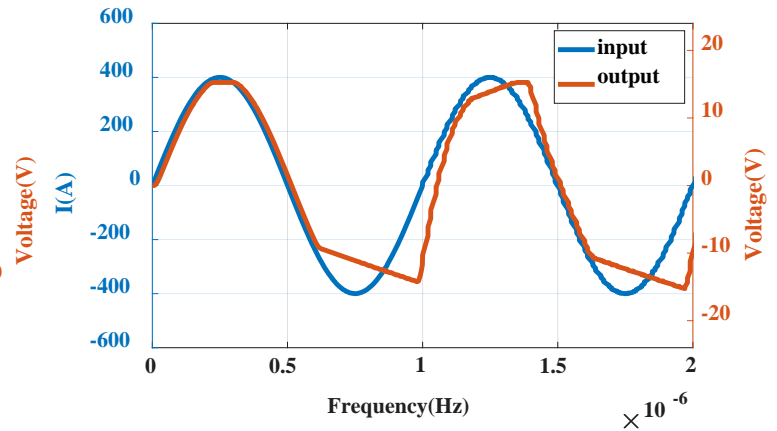

(b) $400 \mathrm{~A}, 1 \mathrm{MHz}$

Figure 14. Sine wave simulation diagrams under different currents

It can be seen from the above figure that the Rogowski coil sensor can respond well to the measured current in the range of $1 \mathrm{~A}-300 \mathrm{~A}$. When the current increases to $400 \mathrm{~A}$, the current output is distorted. It is not difficult to find that the ability of measuring current depends not only on the coil integrator itself, but also on the power supply and coil sensitivity of the operational amplifier. Because the sensitivity of the designed sensor is $40 \mathrm{mV} / \mathrm{A}$ and the supply voltage of op amp is $\pm 15 \mathrm{~V}$, the maximum current is limited to $375 \mathrm{~A}$. So when the current reaches $400 \mathrm{~A}$, the waveform is distorted. To sum up, the PCB Rogowski coil sensor designed in this paper can realize the current measurement at $1 \mathrm{~A}-300$ A, $500 \mathrm{~Hz}-5 \mathrm{MHz}$, with a sensitivity of $40 \mathrm{mV} / \mathrm{A}$, which meets the measurement requirements of the 
breaking current of the PPI chip. Compared with the commercial sensor, it has higher sensitivity and wider measurement range.

\section{Verification of PCB Rogowski Coil Sensor}

\subsection{Experiment of Surge Catastrophe Signal of Rogowski Coil Sensor}

As a standard test instrument, the lightning surge generator is a kind of pulse high-voltage generator which can simulate the time parameters of lightning waves. It can be used to evaluate the anti-interference ability of electrical equipment and electronic equipment. Based on the switching characteristics of the PCB Rogowski coil and compression IGBT designed in this paper, the lightning wave generated by a lightning surge generator is a good choice. Based on the laboratory conditions, lsg-506b of Shanghai Lingshi Electronics Co., Ltd. is selected in this paper, which can generate 10/70 $\mu \mathrm{s}$ open circuit voltage waveform, with the peak value up to $6 \mathrm{kV}$ [32]. The main parameters are shown in Table 3, and the definition of output waveform is shown in Figure 15.

Table 3. Main parameters of lightning surge generator.

\begin{tabular}{cc}
\hline Specification and Model & LSG-506B \\
\hline the front & $10 \mu \mathrm{s} \pm 30 \%$ \\
Pulse width & $700 \mu \mathrm{s} \pm 20 \%$ \\
peak value & $0-6 \mathrm{kV}$ \\
Surge polarity & Positive/negative/positive negative alternation \\
Output impedance & $40,15 \Omega \pm 10 \%$ \\
atmospheric pressure & $86-106 \mathrm{KPa}$ \\
Rated working voltage & $220 \mathrm{~V} \pm 10 \% 50 / 60 \mathrm{~Hz}$ \\
\hline
\end{tabular}

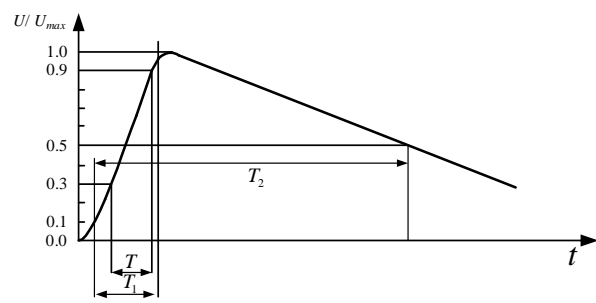

Front time: $T_{1}=1.67 \times T=10 \mu \mathrm{s} \pm 30 \%$

Time to half-value: $T_{2}=700 \mu \mathrm{s} \pm 20 \%$

Figure 15. Output waveform CCITT of LSG-506B.

We select the waveform measured by the Rogowski current waveform transformer (CWT) UM-1 of the PEM company as the reference waveform, put the commercial Rogowski coil and self-made PCB Rogowski coil through the wire, and output them to the oscilloscope. It should be noted that in order to reduce the error, the conductor should be in the center of the Rogowski coil and perpendicular to the plane of the Rogowski coil. In order to verify the differential characteristics of the PCB coil, the output of the coil needs to be directly connected to the oscilloscope through coaxial cable.

We check the wiring, connecting the power supply, and constantly adjust the amplitude of the output voltage of the lightning surge generator; the current waveform can be observed through the oscilloscope.

When the voltage is added to $300 \mathrm{~V}$, the primary waveform is triggered. After data processing by MATLAB, the output waveform is as shown in Figure 16. The red curve represents the differential voltage waveform of the PCB Rogowski coil, and the blue represents the PEM Rogowski coil. It can be seen from the figure that the current waveform rises rapidly from 0 to the highest value and then drops, the output of the self-made coil rises sharply to the highest value and then decreases, then decreases to 
0 , then increases in reverse, and finally increases to 0 . The differential characteristics of PCB Rogowski coil are verified.

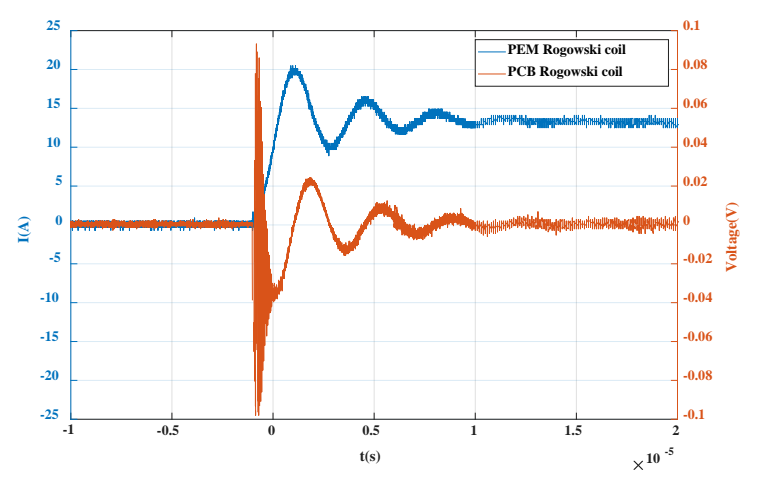

Figure 16. Differential verification waveform of PCB Rogowski coil.

Import the data of oscilloscope into MATLAB, process the data integration, and obtain the measured curve of single PCB coil as shown in Figure 17.

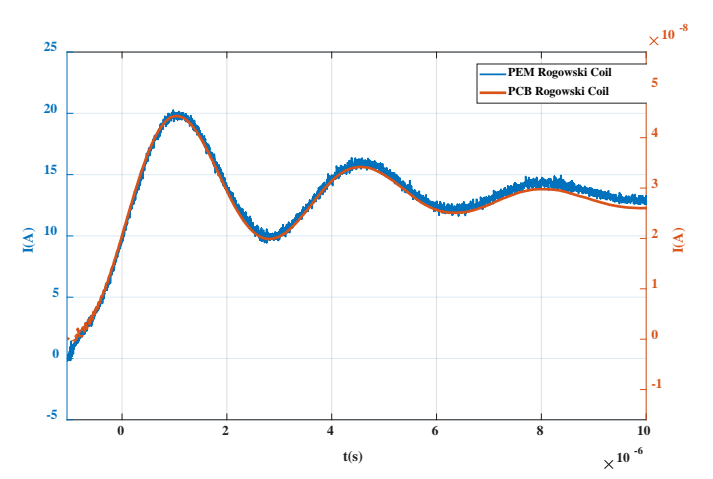

Figure 17. Integral waveform of PCB Rogowski coil.

As can be seen from the Figure 18, compared with commercial sensors, the curve processed by integration in this paper can restore the measured current well, and the waveforms of the two are basically the same.

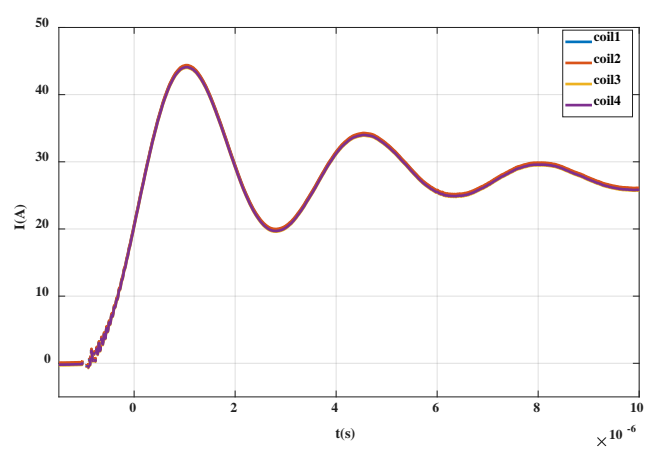

Figure 18. Integrated PCB Rogowski coil integral waveform.

The trigger interval time is set to $20 \mathrm{~s}$. For each integrated PCB Rogowski coil, the numbers are coil1, coil2, coil3 and coil4 (as shown in Figure 19 below). The four coils trigger a surge signal under the voltage of $600 \mathrm{~V}$. After the integration processing, the curve as shown in Figure 19 above is obtained. It can be seen that the measurement results of the four integrated PCB coils are consistent. Through the lightning surge experiment, the advantages of $\mathrm{PCB}$ processing are demonstrated. The $\mathrm{PCB}$ ensures the 
consistency of each coil parameter, and further verifies the feasibility and performance of the integrated PCB Rogowski coil.

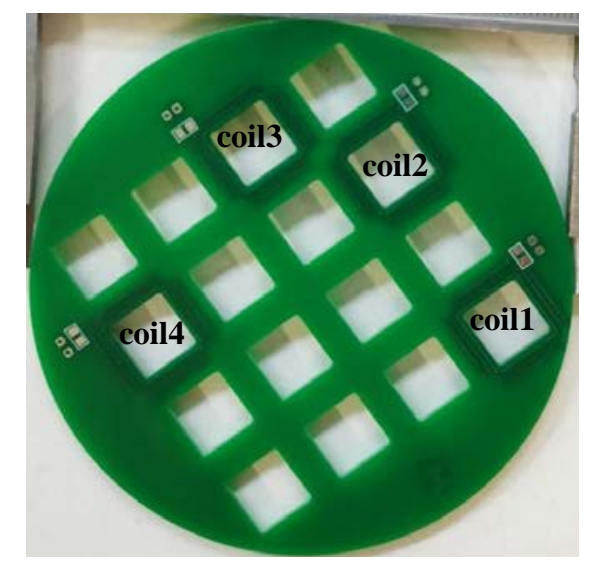

Figure 19. Physical number of integrated PCB Rogowski coil.

\subsection{The Measurement Experiment of the Transient Current of the Crimp IGBT Chip}

At present, the commonly used dynamic test platform for PPI is double the pulse test circuit (as shown in Figure 20 below), which conforms to IEC60747-9 test standard [33]. The circuit structure is simple, and only one pulse drive signal is needed in the test to realize the disconnection of IGBT, and it is more convenient to study the characteristics of IGBT. In this paper, a dual pulse dynamic test platform is built based on the laboratory conditions, and the PCB coil designed by ourselves is used to measure the transient current of the internal chip in order to further verify the performance of the designed PCB Rogowski coil.

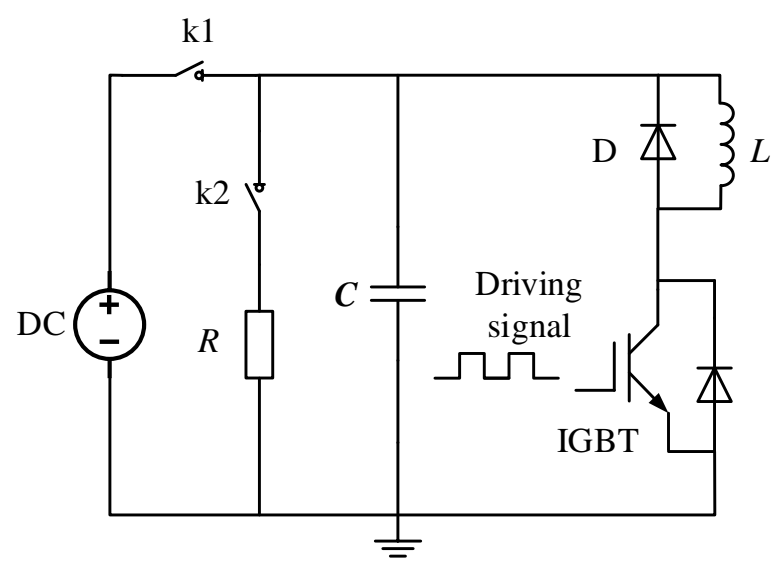

Figure 20. Dual pulse test platform schematic.

We turn on the power, turning on the switch k1, charge the high-voltage capacitor to $300 \mathrm{~V}$, then turn off the switch $\mathrm{k} 1$ with the controller, trigger the optical pulse generator at the same time, and then driving the PPI, connect the PCB Rogowski coil into the oscilloscope through the coaxial cable in advance, thereby observing the current waveform of the IGBT collector. It should be noted that in order to further ensure the safety of the experiment, the power ground wire, high-voltage probe ground wire and the $\mathrm{V}_{\mathrm{CE}} \mathrm{E}$ end of IGBT are all connected with the laboratory ground wire in this experiment.

The main research of the double pulse experiment is the waveform of the first turn-on and the second turn-on of the chip. As shown in Figure 21, when the first tube of the double pulse IGBT is turned off, the waveform measured by PCB Rogowski coil suddenly drops and then rises to 0 ; at the second turn-on, the measured voltage first rises to the highest point, then rapidly drops to 0 , then drops 
in reverse to the lowest point, and finally returns to 0 . This is a good verification of the differential characteristics of the designed PCB Rogowski coil.

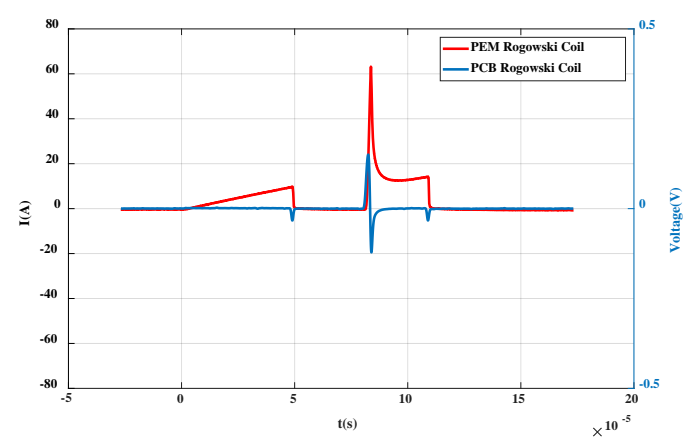

Figure 21. Differential current waveform of PPI.

After integrating the waveform data, the current off and on waveforms are obtained as shown in Figures 22 and 23. It can be seen that the waveforms are basically consistent with the current waveforms measured by commercial CWT Rogowski coil. In the turn-off waveform, analyzing the current drop time, i.e., the time from 0.9 times collector current to 0.1 times collector current, it can be calculated that the current drop time is about $0.3 \mu$ s and the bandwidth is about $3 \mathrm{MHz}$, which is in the frequency band of the composite integrator designed in this paper. During the opening period, due to the influence of parasitic parameters of anti-parallel diodes and inductors, a overshoot of up to 65 A occurs during the opening process. It should be noted that if the overshoot is higher than the specified value of the chip, the reliability of the device will be affected. Therefore, the PCB Rogowski coil designed in this paper can not only monitor the transient breaking current of the crimped IGBT, but also provide a reference for the reliability research of the PPI module.

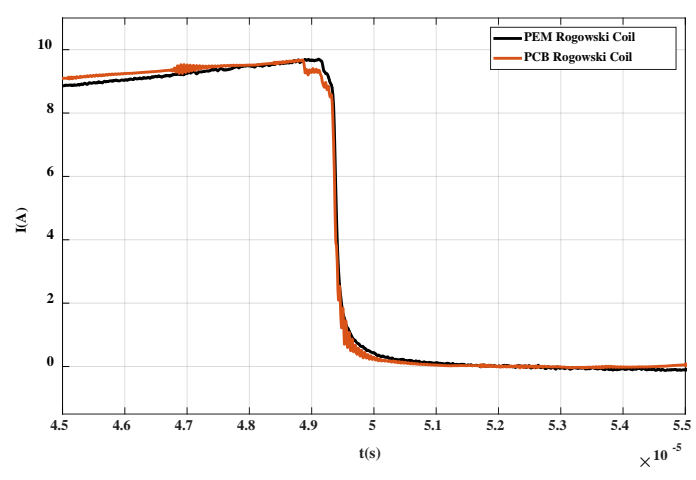

Figure 22. Turn-off current waveform of PPI.

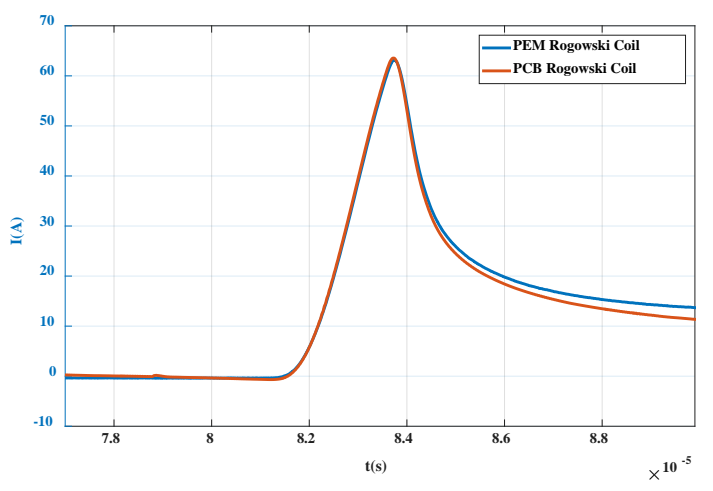

Figure 23. Turn-on current waveform of PPI. 


\section{Conclusions}

In view of the possible uneven current and internal chip current overshoot in the process of switching on and off of each chip of the press-pack IGBT, in this paper a current measurement sensor based on a multilayer PCB Rogowski coil is introduced. On the basis of eliminating large measurement error caused by uneven winding of the traditional Rogowski coil, the sensitivity and anti-interference ability of output voltage are further improved. The integrated PCB Rogowski coil is only $1 \mathrm{~mm}$ thick, which can measure the multi-chip current, and accurately reflect the impulse current waveform under lightning surge and the breaking current waveform of the press-pack IGBT. The sensitivity of the sensor is $40 \mathrm{mV} / \mathrm{A}$, the current measurement capacity is $0-375 \mathrm{~A}$, and the high-frequency bandwidth is about 3 $\mathrm{MHz}$, which can meet the design requirements and current measurement of the IGBT chip. Compared with the standard commercial sensor, the device has lower cost, higher sensitivity, wider measurement capability and easier integration, which provides an important reference for the reliability research of the device.

Author Contributions: Conceptualization, C.J. and Z.Z. (Zhibin Zhao); methodology, C.J. and Z.Z. (Zhibin Zhao); software, Z.Z. (Zuoming Zhang); validation, Z.Z. (Zuoming Zhang) and Z.Z. (Zhibin Zhao); formal analysis, C.J.; investigation, Z.Z. (Zuoming Zhang); resources, Z.Z. (Zhibin Zhao); data curation, Z.Z. (Zuoming Zhang) and X.Z.; writing-original draft preparation, C.J., Z.Z. (Zuoming Zhang); writing—review and editing and C.J. and Z.Z. (Zhibin Zhao); visualization, Z.Z. (Zuoming Zhang); supervision, C.J.; project administration, C.J and X.Z.; funding acquisition, X.Z. All authors have read and agreed to the published version of the manuscript.

Funding: This work was supported by the Science and Technology Project of State Grid Corporation of China: Future Grid Prospective Technology Layout Research (grant no. NYB17201800314) and the open Fund of the State Key Laboratory of Alternate Electrical Power System with Renewable Energy Sources (grant no. LAPS17017).

Conflicts of Interest: The authors declare no conflict of interest

\section{References}

1. Bock, B.; Krafft, E.; Steimel, A. Measurement of multiple chip current in a Press-Pack IGBT using Rogowski Coils. In Proceedings of the 10th European Conference on Power Electronics an Applications (EPE), Toulouse, France, 2-4 September 2003.

2. Müsing, A.; Ortiz, G.; Kolar, J.W. Optimization of the current distribution in press-pack high power IGBT modules. In Proceedings of the 2010 International Power Electronics Conference, Sapporo, Japan, 21-24 June 2010; pp. 1139-1146.

3. Alvarez, R.; Bernet, S. A new delay time compensation principle for parallel connected IGBTs. IEEE Energy Convers. Congr. Expo. (ECCE) 2011. [CrossRef]

4. Alvarez, R.; Bernet, S. Sinusoidal Current Operation of Delay-Time Compensation for Parallel-Connected IGBTs. IEEE Trans. Ind. Appl. 2012, 50, 3485-3493. [CrossRef]

5. Mo, S.; Zhao, Z.; Sun, P.; Lu, Y.; Tang, X. Influence of package parasitic inductance on transient current distribution characteristics of press pack igbt. In Proceedings of the 2017 Sixth Asia-Pacific Conference on Antennas and Propagation (APCAP), Xi'an, China, 16-19 October 2017.

6. Long, H.Y.; Sweet, M.R.; Narayanan, E.M.S.; Li, G. Reliability study and modelling of IGBT press-pack power modules. In Proceedings of the 2017 IEEE Applied Power Electronics Conference and Exposition (APEC), Tampa, FL, USA, 26-30 March 2017; pp. 2711-2717.

7. Zhu, N.; Chen, M.; Yan, R.; Mantooth, A.; Xu, D. Die Current Balancing of a Press-Pack SiC MOSFET. In Proceedings of the 2018 IEEE Energy Conversion Congress and Exposition (ECCE), Portland, OR, USA, 23-27 September 2018; pp. 5824-5830.

8. Chen, Z.; Zhang, X.; Pan, Y.; Li, J. Research on the Current Distribution Characteristics within a Single Chip of press pack IGBT. In Proceedings of the 2018 IEEE International Power Electronics and Application Conference and Exposition (PEAC), Shenzhen, China, 4-7 November 2018.

9. Xianwei, M.; Mengyue, H.; Heli, M.; Yangchun, C.; Jun, Z. Research on the Measuring System for IGBT Current Distribution. In Proceedings of the 2018 IEEE International Conference on High Voltage Engineering and Application (ICHVE), Athens, Greece, 10-13 September 2018. 
10. Deng, Z. Influence of Uneven Pressure Distribution on Current Distribution in Paralleled Multi-Chips Press Pack IGBT. Smart Grid 2020. [CrossRef]

11. Li, H.Y.; Jiang, G.X. A Rogowski coil of $\mathrm{nS}$ order for measuring fast-rising high current. Adv. Technol. Electr. Eng. Energy 1989, 40-45.

12. Li, H.Y.; Yu, C.Y.; Jiang, G.X. Development of nanosecond Rogowsky coil. J. Xi'an Jiaotong Univ. 1991, 25, $41-46$.

13. Bing, W.; Zhen, F.; Yujuan, W.; Dynasty, G.Y.; Bing, M. Frequency response analysis of passive RC integrator. High Volt. Technol. 2008, 34, 53-56.

14. Gerber, D.; Guillod, T.; Biela, J. IGBT gate-drive with PCB Rogowski Coil for improved short circuit detection and current turn-off capability. In Proceedings of the IEEE Pulsed Power Conference, Chicago, IL, USA, 19-23 June 2011; pp. 1359-1364.

15. Gerber, D.; Guillod, T.; Leutwyler, R.; Biela, J. Gate Unit with Improved Short-Circuit Detection and Turn-Off Capability for 4.5-kV Press-Pack IGBTs Operated at 4-kA Pulse Current. IEEE Trans. Plasma Sci. 2013, 41, 2641-2648. [CrossRef]

16. Minjiang, X. Research on the Characteristics and Application Technology of Traveling Wave Based on Rogowski coil. Ph.D. thesis, Shandong University, Shandong, China, 2013.

17. Liu, Y.; Xie, X.; Hu, Y.; Qian, Y.; Sheng, G.; Jiang, X. A Novel Transient Fault Current Sensor Based on the PCB Rogowski Coil for Overhead Transmission. Sensors 2016, 16, 742. [CrossRef] [PubMed]

18. Tao, T.; Zhao, Z.; Ma, W.; Pan, Q.; Hu, A. Design of PCB Rogowski Coil and Analysis of Anti-interference Property. IEEE Trans. Electromagn. Compat. 2016, 58, 344-355. [CrossRef]

19. Koga, M.; Tsukuda, M.; Nakashima, K.; Omura, I. Application-specific micro Rogowski Coil for power modules-Design tool, novel coil pattern and demonstration. In Proceedings of the CIPS 2016, 9th International Conference on Integrated Power Electronics Systems, Nuremberg, Germany, 8-10 March 2016.

20. Tsukuda, M.; Koga, M.; Nakashima, K.; Omura, I. Micro PCB Rogowski Coil for current monitoring and protection of high voltage power modules. Microelectron. Reliab. 2016, 64, 479-483. [CrossRef]

21. Tsukuda, M.; Nakashima, K.; Tabata, S.; Hasegawa, K.; Omura, I. Clamp type built-in current sensor using PCB in high-voltage power modules. Microelectron. Reliab. 2017, 76, 517-521. [CrossRef]

22. Jun, Y.; Li, G.; Liu, H.; Yang, G.; Ling, G. Design of a flexible rogowski coil with active integrator applied in lightning current collection. In Proceedings of the 2016 33rd International Conference on Lightning Protection (ICLP), Estoril, Portugal, 25-30 September 2016.

23. Habrych, M.; Wisniewski, G.; Miedzinski, B.; Lisowiec, A.; Fjałkowski, Z. HDI PCB Rogowski Coils for Automated Electrical Power System Applications. IEEE Trans. Power Deliv. 2018, 33, 1536-1544. [CrossRef]

24. Lei, M.; Zhen, X.; Changqing, Y. Screen-Returned PCB Rogowski Coil for the Switch Current Measurement of $\mathrm{SiC}$ Devices. In Proceedings of the 2019 IEEE Applied Power Electronics Conference and Exposition (APEC), Anaheim, CA, USA, 17-21 March 2019; pp. 958-964.

25. Gu, P.Y.; Chen, Q.; Li, H.B.; Hu, C.; Gong, H.; Jiao, Y. PCB Rogowski Coils for 300kA Current Measurement on a Multi-Split Conductor. IEEE Sens. J. 2019, 19, 6786-6794. [CrossRef]

26. Ming, L.; Xin, Z.; Liu, W.; Loh, P.C. Structure and modelling of four-layer screen-returned PCB Rogowski coil with very few turns for high-bandwidth SiC current measurement. IET Power Electron. 2020, 13, 765-775. [CrossRef]

27. Wang, J.; Chen, W.; Chen, P. A Design Method of Pcb Rogowski Coil in Limited Space and Modified Integral Circuit. IEEE Sens. J. 2020, 20, 5801-5808. [CrossRef]

28. Rogowski, W.; Steinhaus, W. Die Messung der magnetischen Spannung. Archiv. Für Elektrotechnik 1912, 1, 141-150. [CrossRef]

29. Ramboz, J.D. Machinable Rogowski Coil, design and calibration. IEEE Trans. Instrum. Meas. 1996, 45, 511-515. [CrossRef]

30. Wang, C.; Chen, Y.; Zhang, G.; Zhou, Z. Design of Printed-Circuit Board Rogowski Coil for Highly Accurate Current Measurement. In Proceedings of the International Conference on Mechatronics and Automation, Harbin, China, 5-9 August 2007; pp. 3801-3806.

31. Ahmed, A.; Coulbeck, L.; Castellazzi, A.; Johnson, C.M. Design and test of a PCB Rogowski coil for very high $\mathrm{dI} / \mathrm{dt}$ detection. In Proceedings of the 15th International Power Electronics and Motion Control Conference, EPE-PEMC 2012 ECCE Europe, Novi Sad, Serbia, 4-6 September 2012. 
32. Electromagnetic Compatibility-Test and Measurement Techniques-Surge Immunity Test. Available online: https://global.ihs.com/doc_detail.cfm?document_name=IEC\%2061000\%2D4\%2D5\&item_s_key= 00223184 (accessed on 2 May 2020).

33. Semiconductor Devices-Discrete Devices-Part9: Insulated-Gate Bipolar Transistors (IGBTs). Available online: https://webstore.iec.ch/publication/32214 (accessed on 2 May 2020).

(c)

(C) 2020 by the authors. Licensee MDPI, Basel, Switzerland. This article is an open access article distributed under the terms and conditions of the Creative Commons Attribution (CC BY) license (http://creativecommons.org/licenses/by/4.0/). 